LICENÇA CC BY:

Artigo distribuído sob os termos

Creative Commons, permite uso e distribuição irrestrita em qualquer meio desde que o autor credite a fonte original.

\title{
MOVIMENTO CULTURAL ARTE MANHA: LUGAR DA ARTE, CORPO E MEMÓRIA AFRO-INDÍGENA NA ESCOLA, CARAVELAS, BA
}

THE ARTE MANHA CULTURAL MOVEMENT: THE PLACE OF ART, BODY AND AFRO-INDIGENOUS MEMORY IN SCHOOL, CARAVELAS, BA MOVIMIENTO CULTURAL ARTE MANHA: LUGAR DE ARTE, CUERPO Y MEMORIA AFRO-INDÍGENA EN LA ESCUELA, CARAVELAS, BA

Maria de Fátima de Andrade Ferreira ${ }^{1}$

Maria Rosário Gonçalves de Carvalho²

'Departamento de Ciências Humanas, Educação e Linguagem, Universidade Estadual do Sudoeste da Bahia, Jequié, BA, Brasil.

2Programa de Pós-Graduação em Antropologia Social, Universidade Federal da Bahia, Salvador, BA, Brasil.

Artigo recebido em: $31 / 03 / 2020$

Aprovado em: 15/11/2020

Resumo: Neste artigo, apresento um recorte da etnografia realizada sobre relações interétnicas com um grupo de pessoas que se autodeclaram afro-indígena, em Caravelas, BA e pertence ao Movimento Arte Manha, criado em 1988, com objetivo de luta e resistência negra e indígena. Nele, procuro descrever o lugar da arte, corpo e memória afro-indígena no movimento e na escola, tratando de redes de sociabilidades, "encontros" e zonas de contato. A escolha do tema, como recorte para este trabalho, é o fato de que o grupo trouxe provocações, quando traz repertórios sócio-históricos de suas culturas de origem, a valorização das africanidades do legado africano e a cultura indígena e, por meio de estratégias, se apropria da arte, do corpo e da memória (BOSI,1994) como instrumentos de luta, resistência e práticas educativas. É assim que os afro-indígenas de Caravelas conduzem as teias da memória e a construção de um passado que, por sua vez, é também fruto de criação e de novas experiências subjetivas e afro-indígenas, focando o corpo como centro das políticas, no sentido de (des)racializar e pluralizar espaços sociais, arte, objetos e coisas e traçam esse percurso em busca da memória e da ancestralidade. Na escola, as ações dependem da "necessidade" do grupo, chamadas de interdisciplinares, como entalhe em madeira, desenhos, danças africanas indígenas, roda de conversa para discutir modos de vida afro-indígena. E a escola é espaço privilegiado à realização de ações artístico-culturais. $\mathrm{O}$ espaço de trocas de saberes e conhecimentos se estabeleciam entre os participantes de modo transversal. 
Palavras-chave: Relações afro-indígenas; Arte-corpo; Práticas educativas.

Abstract: This article presents an excerpt of the ethnography on inter-ethnic relations conducted with a group of self-declared Afro-indigenous, in Caravelas, BA, all of whom belong to the Arte Manha Movement, created in 1988 in the context of the Black and indigenous struggle and resistance. This article describes the place of art, body and Afro-indigenous memory in the movement and in schools, addressing social networks, "meetings" and contact zones. This theme was chosen as a cut-out for this work because the group brought provocations when it brings socio-historical repertoires of their cultures of origin, the appreciation of the Africanities of the African legacy and the indigenous culture and, through strategies, appropriates art, body and memory (BOSI, 1994) as instruments of struggle, resistance and educational practices. This is how the Afro-indigenous people of Caravelas lead the networks of memory and the construction of a past that, in turn, is also the result of creation and of new subjective Afro-indigenous experiences, focusing the body as the center of policies in the sense of (dis)racializing and pluralizing social spaces, art, objects and things, and trace this path in search of memory and ancestry. In the school, the actions depend on the "need" of the group, called interdisciplinary, such as wood carving, drawings, indigenous African dances, and conversations to discuss Afro-indigenous ways of life. The school is an ideal space for carrying out artistic-cultural actions. Thus, as space for exchanging knowledge was established between the participants in a transversal way.

Keywords: Afro-indigenous relations; Body-art; Educational practices

Resumen: En este artículo presento un recorte de la etnografía realizada sobre las relaciones interétnicas con un grupo de personas que se autodenominan afro-indígenas, en Caravelas, BA y pertenecen al Movimiento Arte Manha, creado en 1988, con el objetivo de la lucha y resistencia negra e indígena. En él, trato de describir, el lugar del arte, el cuerpo y la memoria afro-indígena en el movimiento y en la escuela, tratando de redes de sociabilidad, «reuniones» y zonas de contacto. La elección del tema, como un recorte para este trabajo es el hecho de que el grupo mostró provocaciones cuando trajo repertorios sociohistóricos de sus culturas de origen, la valorización de las africanidades del legado africano y la cultura indígena y, a través de estrategias, se apropia de arte, cuerpo y memoria (BOSI, 1994) como instrumentos de lucha, resistencia y prácticas educativas. Así es como los pueblos afro-indígenas de Caravelas lideran redes de memoria y la construcción de un pasado que, a su vez, es también el resultado de la creación y nuevas experiencias subjetivas y afro-indígenas, enfocando al cuerpo como el centro de las políticas, en el sentido de (dis)racializar y pluralizar espacios sociales, arte, objetos y cosas y rastrear este camino en busca de memoria y ascendencia. En la escuela, las acciones dependen de la «necesidad» del grupo, llamada interdisciplinaria, como el tallado en madera, dibujos, danzas indígenas africanas, conversación para discutir formas de vida afro-indígenas y la escuela es un espacio privilegiado para llevar a cabo acciones artístico-culturales. El espacio de intercambio de saberes y conocimientos se establecieron entre los participantes de manera transversal.

Palabras clave: Relaciones afro-indígenas; Arte-cuerpo; Prácticas educativas.

\section{Introdução}

A vivência e o contato colonial entre brancos europeus, índios, negros e asiáticos foram marcados por trocas, mitos, lendas, usos, costumes, tramas e intensos conflitos entre esses 
povos. Acontecimentos que marcaram a história de Caravelas e de sua população e se mistura com o início da história da colonização do Brasil de 1500, com a chegada dos europeus.

Caravelas é uma belíssima e encantadora cidade litorânea, um lugar para se viver bem, fica no Extremo Sul da Bahia e, como se sabe, é reconhecida como marco histórico e simbólico na construção de narrativa do início do Brasil e considerada um espaço hospitaleiro, agregador, onde quem visita quer morar ou voltar, não pela sua história oficial e colonizadora, construída pelos europeus, mas pela criatividade, força, hospitalidade de seus moradores, em especial, dos nativos que resistiram e ainda resistem até hoje, as manifestações de (pre)conceitos, discriminação, estereótipos e descaso do poder local, estadual e federal.

Nesta cidade, o Grupo Afro-indígena de Antropologia Cultural Umbandaum está prestes a completar 32 anos de existência, em 13 de maio de 2020 e o Movimento Cultural Arte Manha, sua instituição, completará 28 anos. O grupo surgiu primeiro de uma longa história que merecia um estudo mais aprofundado sobre seus processos políticos, luta e resistência afro-indígena em Caravelas, criados por um grupo composto de jovens estudantes, moradores de periferia de uma cidade do interior, na Avenida da Liberdade, reconhecida por eles como avenida "Graças a Deus" e pelos moradores do centro urbano, como avenida "Deus me Livre", situada no bairro Nova Coreia. Hoje, denominada de avenida Dr. Sócrates Ramos.

Assim como o espaço onde nasceram, viveram a sua infância, adolescência e juventude e aonde vivem até os dias atuais, o grupo de jovens também passou por muitas mudanças e ainda está à procura de transformação em contínuos movimentos sociais e artístico-culturais, principalmente após levantar a sua bandeira de luta, ocupação e proliferação de valores, voltados para a cultura e arte indígena, africana e afro-brasileira, heranças de seus antepassados.

O grupo apresenta provocações e curiosidade quando traz repertórios sociais e históricos de suas culturas de origem, a valorização das africanidades do legado africano e a cultura indígena e, através de estratégias, o grupo apropria da arte, do corpo e da memória como instrumentos de luta e reivindicação por espaço, cidadania, respeito à diversidade, o teatro como encontro, presença, contato e cumplicidade que evidencia o corpo-arte, a arte-corpo e o corpo-memória, por meio da dança, da música, da pintura corporal e "desenho observado", da percussão, do teatro, do corpo sensibilidade. O que diz o grupo sobre corpo, arte e memória? Qual o lugar do corpo na relação afro-indígena de Caravelas? E o lugar da arte?

Antes de tudo, é importante destacar que o tema relação e saberes afro-indígenas não é novo, mas vem despertando o interesse de pesquisadores, por exemplo, Anjos (2006), Anjos \& Oro (2009), Goldman (2014), Mello (2003), Pacheco (2017) e outros, dedicados a encontrar a melhor maneira de discutir relações interétnicas e (contra)mestiçagem. Isto é, um processo que tenta se livrar do mito das três raças (branco, índio e negro), refletir sobre a forma de pensar das classes dominantes que "têm o mau costume de produzir efeitos muito reais" e, assim, temos que nos livrar do conceito de suas dimensões representacionais ou mesmo estruturais (GOLDMAN, 2015, p. 654), abrindo espaço para novas formas de expressão artístico-cultural. 
O termo "relação afro-indígena" é utilizado por Goldman (2014) para designar agenciamentos entre afrodescendentes e indígenas no continente americano e a noção de afro-indígena, de acordo com Mello (2003), tal como concebida pelo "movimento cultural do extremos sul baiano, grupo por ela estudado", "seria da ordem do devir", "do que se torna, do que se transforma em outra coisa diferente do que se era e que, de algum modo, conserva uma memória do que se foi" (p. 95), um "devir-afro-indígena", que funciona, por um lado, "como meio, um intercessor por onde passam ideias, ações políticas, obras de arte e seres do cosmos e, por outro, como "um produto inacabado ou efeito provisório de encontros singulares que envolveriam fluxos de 'história' e 'memória'" (MELLO, 2014, p. 223) e, pode ser definido como novas conexões e diferenciações entre coletivos que se dão de variadas formas e em diversos contextos socioculturais e espaço-temporais.

Embora tenha no título "o lugar da arte, corpo e memória", não é intenção, aqui, discutir o que é ou não é arte, corpo e memória, pois esse não é o foco deste estudo. No entanto, apresenta concepções de arte, corpo, memória, pautada em Bosi (1994) e outros, para compreender de que forma os corpos do movimento de Caravelas desenham na artecorpo, corpo-arte, corpo-memória, na dança, no teatro, nos processos educativos, relação com sua identidade étnico-racial e constrói suas zonas de contato, teias de cultura, de práticas educativas, de interações e saberes afro-indígenas, trabalhando com alunos na escola e nas oficinas em dois espaços do movimento, o Dandara Zumbi e sede do Arte Manha.

Neste artigo, apresento um recorte da etnografia sobre relações interétnicas com um grupo de pessoas que se autodeclara afro-indígena e pertence ao Arte Manha, com objetivo de luta e resistência negra e indígena, realizada em Caravelas, no Extremo Sul da Bahia, em 2018-2019. Nele, procuro descrever o lugar da arte, corpo e memória afro-indígena na escola - um espaço que o movimento realiza atividades que se cruzam valorizando a interlocução entre arte, corpo, educação e memória, tratando de redes de sociabilidades, "encontros" -, uma estratégia para construir novas zonas de contato, amigos, parceiros e continuar a luta e resistir. A justificativa para a escolha do tema como recorte para este trabalho é o fato de que o grupo trouxe provocações quando trouxe repertórios sócio-históricos de suas culturas de origem, valorização das africanidades do legado africano e cultura indígena e, através de estratégias, se apropria da arte, corpo e memória (BOSI,1994) como instrumentos de luta e resistência.

A pesquisa buscou ouvir e compreender, a partir de situações práticas, os modos que essas pessoas se apresentam e pensam como índios e negros e o convívio interétnico em um espaço multiétnico e de valorização do corpo e arte como território intercultural, um "local de cultura" (BHABHA, 2013). Ao que parece, esta é "uma encruzilhada" que se caracteriza como um espaço onde se encontram diferentes caminhos que seguem sem se fundir (ANJOS, 2006), uma mestiçagem pensada sob o ponto de vista etnográfico, uma antimestiçagem (LUCIANI, 2016) e/ou (contra)mestiçagem (GOLDMAN, 2014), a constituição de um espaço urbano onde se pode encontrar parentes, combater estereótipos, (pre)conceitos e discriminação; um lugar onde se pode falar-pensar e saber-fazer antropologia e uma experimentação etnográfica. 
As redes sociais são diversas e, permanentemente, usadas para fazer parentes, trocas de saberes e divulgar o Ponto de Cultura que mantém no espaço de ações, que gera novos saberes, formas de relações sociais e experiências de alteridade, que orienta crianças "a passarinhar " oficinas de desenhos observados sob a orientação de Dó, um dos coordenadores do movimento e responsável pelo Ateliê Astúcia - núcleo de artes plásticas, entalhe de madeira, escultura, desenhos observados, pintura, geração de renda com fabrico de móveis com reciclagem e de madeira reaproveitada, olaria, decoração com materiais alternativos, costura, serigrafia, criação de adornos e alegorias para os grupos culturais do local, ornamentação das ruas no carnaval e outras atividades, "necessidades do movimento". As redes de encontros, zonas de contato e trocas de saberes afro-indígenas, mantidas pelo grupo, nos leva a interpretar teias como redes de comunicação, cujo sentimento de pertença ao espaço de trocas e simbólica se constitui em microgrupos, "tribos que pontuam a espacialidade" (MAFFESOLI, 1987, p. 194) e exige novos comportamentos, atitudes, performance diferenciada em relação a outros espaços e "se faz a partir do sentimento de pertença, em função de uma ética específica e no quadro de uma rede de comunicação" (p. 194). Nesse processo, foi possível observar relações culturais e sociais do grupo e o modo que se organiza no espaço e como se dá significado(s) ao lugar onde vive e à memória individual e coletiva - "representações partilhadas do passado ou as que supostamente o são, as circunstâncias da sua emergência - as suas expressões concretas, particulares e observáveis" (CANDAU, 2005, p. 12).

A escola é um dos espaços privilegiados pelo movimento para realizar ações, lugar socioeducativo preferido e ponto de referência de sociabilidades, adequado a desenvolver consciência política e contar história de seus antepassados, em oficinas de dança, teatro, música, artes plásticas, pinturas corporais, trancinhas, participação em bloco de carnaval e grupo de percussão e de construção de instrumentos musicais utilizados pelo próprio grupo como modos de saber-fazer e pensar arte-corpo, construção memorial de diferentes heranças deixadas por suas ancestralidades, "encontros" e relatos de experiências vividas.

\section{Contatos interétnicos, (contra)mestiçagem e relação afro-indígena à luz de teorias etnográficas recentes}

No primeiro momento da colonização do Brasil, diferentes ideologias sobre a terra e os índios brasileiros, sucessivamente, foram povoando o pensamento dos colonizadores e colonizados, permitindo formas de relações amistosas, de aceitação e/ou de resistência, entre índios, europeus e, a partir de "Quinhentos", se juntou a negros africanos e afro-indígenas.

Os contatos interétnicos entre colonizadores e colonizados sempre buscavam apagar os vestígios culturais, o primeiro entre missionários, viajantes e povos indígenas do litoral e, posteriormente, do sertão, seja através dos aldeamentos, que tinham como objetivo "civilizar" e "(re)educar" aquela gente e catequizá-los de acordo com a realidade da política colonial, ou por "guerras", combates bélicos que dizimaram grande parte dessa população, sem precedentes. E 
o segundo, entre negros africanos, trabalhadores escravos, viajantes e colonizadores, quando os negros foram submetidos a mecanismos de reprodução das relações desiguais sempre violentos, com castigos físicos, mas também os negros utilizaram diferentes estratégias, ora de resistência, ora de acomodação, para conseguir melhor tratamento e condição de vida.

As fontes utilizadas (COSTA, 2001; GOLDMAN, 2015 e outros) apresentam que, apesar dos numerosos obstáculos, a colonização do Brasil provocou o encontro entre índios, negros e afro-indígenas e, nas zonas de contato e trocas culturais, "desvendaram saberes, fazeres, crenças, costumes, tradições e formas de luta de populações tradicionais orais historicamente invisibilizadas ou estereotipadas pelo poder das escritas colonialistas" (PACHECO, 2017). Nesse contexto, o termo mestiçagem "possui pelo menos três empregos mais importantes". A ideologia da mestiçagem e branqueamento foi sendo construída sobre questões de raça e etnia e provocada devido à diversidade racial na sociedade brasileira e foi muito presente entre o século XIX e XX, fase da segunda expansão europeia. Segundo relatos desse período, a recorrência das ideologias raciais (ALENCASTRO, 1985) foi conflitiva e incoerente, um fenômeno perverso e "empregado para classificar comunidades humanas, mas igualmente para estabelecer entre elas hierarquia justificadora da dominação política e o conceito de raça permanece marcado pela imprecisão científica e por condicionantes ideológicas" (p. 50).

Nos ambientes inter-relacionais, o índio, o negro e o afro-indígena, mesmo diante dos obstáculos, buscaram desvelar espaços de moradia, trabalho, celebrações religiosas e territórios, construindo espaços onde pudessem operar astúcias de suas memórias, (re)produzir e (re) afirmar cosmologias, imaginários e representações de vida (PACHECO, 2011). Logo, é preciso desconstruir o conceito de mestiçagem (GOLDMAN, 2014) e reconhecer o seu emprego como "uma forma de exclusão social e cultural, na medida em que este de fato justifica e legitima a posição inferior dos não-brancos" (COSTA, 2001, p. 144). Vale salientar, por isto, que a vivência e o contato colonial entre brancos europeus, índios, negros e asiáticos foram marcados por trocas, mitos, lendas, usos, costumes, tramas e intensos conflitos entre esses povos. No caso brasileiro, especificamente, a ideia de mestiçagem significa a mistura entre brancos, índios e negros e carrega uma complexidade que envolve questões políticas, históricas, culturais, ideológicas e não aceita a diferença.

Diante destes problemas colocados por Alencastro (1985), Costa (2001), Goldman (2014), é preciso destacar que há muitas questões que impedem a desconstrução da noção de mestiçagem, por exemplo, ter pouco conhecimento a respeito da história e das condições de existência das populações indígenas e afrodescendentes, mesmo com a maciça presença destes povos na sociedade brasileira.

\section{O corpo, a arte e a memória como categorias etnográficas}

O corpo, a arte e a memória são categorias de análise que têm suscitado diferentes discussões no campo das ciências; e a Antropologia, a Etnologia e a Etnografia têm se destacado 
no entendimento de que é com o corpo que marcamos nossa presença no mundo, contamos a nossa história, ou, ainda, o corpo como o arcabouço simbólico da sociedade, signo das representações coletivas, aponta Mauss (2003).

Os movimentos artístico-culturais do corpo, os cheiros, os gostos, os gestos, os espaços organizados conduzem às teias da memória e à (re)construção de um passado que, por vez, é também fruto de uma criação e de novas experiências subjetivas associadas à população afrodescendente e indígena no Brasil. Esse conjunto de coisas, objetos, artes e acontecimentos nos permite percorrer trilhas ainda pouco conhecidas e que nos leva a pensar o quanto ainda estamos distantes de uma história de (contra)mestiçagem e afro-indígena "verdadeiramente digna deste nome" e de atenção, como nos ajuda a pensar Marc Bloch (1982). Desse jeito, o corpo permite estabelecer formas de sociabilidade, de sentir, pensar e expressar a relação entre afrodescendentes e indígenas, construir marcas identitárias e de distinção social (CASTRO, 2004).

Nas trilhas de Bloch (1982, ) e Castro (2004), juntam-se os pedaços de retalhos que foram encontrados durante o percurso da etnografia, que sinaliza caminhos à procura de fontes que proporcionassem contornos à produção etnográfica, por exemplo, pinturas, fotografias, objetos de artes produzidos pelos afro-indígenas de Caravelas, que foram se incluindo como fontes relevantes para entender o saber-fazer do grupo em questão e possíveis da descrição etnográfica e formulação de questões sobre o objeto em análise. E, também, permitiu pensar a relação afro-indígena de Caravelas através do princípio da (contra)mestiçagem/(anti) mestiçagem, tendo o corpo, a arte e a memória como categorias principais de análise, em especial, quando foi possível pensar o corpo como expressão de identidades, de lugar de memórias e sensibilidades; e observar suas diferentes formas de simbolização na vida social, visto como suporte de identidades afro-indígenas, de memórias e subjetivações de encontros entre afrodescendentes e indígenas em Caravelas.

Memória é uma vivência do passado e o corpo um instrumento de luta e resistência. Há uma memória escrita no corpo (ANTONACCI, 2014) e as marcas corporais são linguagens importantes em diferentes culturas e, para os escravos fugitivos, serviam para registrar a vida, o sentimento de pertencimento a este ou àquele grupo. Os fugitivos, quando eram resgatados pelos capatazes, sofriam castigos diversos e mais duros e, certamente, ficavam com cicatrizes no corpo, que também serviram para registrar um momento que nunca foi e não será esquecido. $\mathrm{E}$, mais ainda, as marcas servem para registrar a memória do grupo de pertencimento.

Nas trilhas de Velloso, Rouchou e Oliveira (2009), podemos afirmar que essas questões poderiam expressar tamanho estranhamento, mas é através do corpo que:

(...) expressamos sensações, sentimentos, emoções e estabelecemos relação com os que nos cercam, com o mundo e com a cultura. Pensar o corpo é deparar-se com uma obra em aberto, para sempre inconclusa, como são as bases culturais que o constituem, nomeiam e transformam, através dos tempos e da história. (2009, p. 15).

A partir dessa compreensão sobre o corpo, é possível pensar a memória com uma outra categoria indispensável à simbolização dos corpos afro-indígenas e o corpo como principal instrumento da arte, pois é com o corpo que também se lembra, recorda, imita, representa, 
dança, recita, expressa sentimentos e pensamentos, pula, encanta, gesticula, provoca, promove encontros, acontecimentos, firmam-se colaborações e alianças. Antonacci (2014) destaca que o corpo está impregnado de "evocações, histórias, percepções e sensibilidades", por que não dizer, que ele é um "arquivo vivo de lembranças e memórias marcadas pela violência física e simbólica" entre índios, negros e colonizadores, quando se trata, por exemplo, de relações entre africanos, indígenas, afrodescendentes, situadas em zonas de contato, que tiveram que reinventar as suas lembranças no corpo a corpo, alterando formas de viver, de sentir e de se comunicar.

O corpo fala, comunica, dialoga, relaciona através de contatos, das ciências, das manifestações do conhecimento e dos saberes e é com o corpo que marcamos a nossa presença no mundo; através dele expressamos nossos sentimentos, sensações, aborrecimentos, emoções, afetos e estabelecemos relação com os outros, com o mundo e com a(s) cultura(s). $E$, ainda, pode-se acrescentar que o corpo é um mecanismo de linguagem e, junto ao corpo e à memória, a arte "só pode nos falar das verdades ambíguas da existência e o corpo é o seu canal de expressão e manifestação de resistência e é capaz de traduzir cenários nos quais se move, reivindica, vive" (2014, p. 120). A autora lembra que "os corpos africanos, plasticamente modelados na confluência de forças e energias da natureza, assumiram esse perfil como expressão cultural de suas vivências, cosmovisões e formas de inserção no mundo" (p. 125).

Nesse sentido, a questão levantada por Santa'Anna (2001) traz a concepção de que o corpo não é mais uma unidade, mas um elo entre os corpos e, assim, somos e temos um corpo sempre de passagem, pois o corpo pode assumir formas, comportamentos, em diferentes momentos, pode estar parado ou em movimento, envolto pela subjetividade, o corpo toma forma, sentidos, construindo identidades. A música, o batuque do tambor, a coreografia e a dança exercem um papel importante no cotidiano das pessoas e, "em contínuo negociar e refazer de suas inserções, povos e linguagens africanas seletivamente (re)significaram suas tradições, reinventando Áfricas no Novo Mundo. Áfricas de difícil recriação e reconhecimento", diz Antonacci (2014, p.17).

Os africanos e seus descendentes foram silenciados, folclorizados, estetizados ou demonizados por concepções de vida e história predominantes do Ocidente; seus sinais iluminam memórias ancoradas em corpos negros; do corpo e de seus prolongamentos materiais e acústicos afloram costumes africanos. No pensamento de Santos (2018), estas práticas conjugam elementos importantes sobre a ancestralidade dos povos tradicionais, de africanidade, por exemplo, e abre possibilidades à constituição da memória e à continuidade de práticas ancestrais herdadas e reinventadas por negras e negros. Desse modo, "estas práticas conjugam elementos que só podem ser apreendidos por meio de prismas de análise não cartesianos" (p. 144). Sobre essa questão, Antonacci afirma que,

Ao conjugar narrativas da diáspora no Brasil, despontaram linguagens corporais e sensibilidades de herdeiros de matrizes orais africanas, prefaciando disjunções sonoras e gestuais. Nestas, protagonistas de histórias e culturas orais, em regime de símbolos e de energias de seus corpos comunitários, traduziram traumas e transgressões a sofrimentos cotidianos. (2014, p. 17). 
Nessa lógica, o artista é o intelectual que desencadeia sensibilidades e percepções em comunidades onde imbricações letra e corpo marcam presença, lembrando que Pratt (1999, p. 16) "aponta ser a 'descolonização do conhecimento e da mente uma tarefa incrível, na qual intelectuais e artistas devem permanecer como colaboradores durante gerações'" (apud ANTONACCI, 2014, p. 350). E "em corpo a corpo cultural, 'vozes do corpo' configuram 'memórias sem arquivos vivos', em 'performance presencial', conforme estudiosos de culturas e da voz do corpo" (p. 352), a exemplo de Certeau (1996).

Conforme os argumentos interpretativos de Bartolo (2007, p. 3), "todos temos um corpo que sentimos, partilhamos" e que também nos constrange morfologicamente (somos altos, baixos, gordos, magros), patologicamente (sentimos dor, cansaço, sonolência), emocionalmente (sentimos alegria, tristeza) e socialmente (somos normais, anormais, adequados, desadequados, educados, deseducados). O autor lembra que são esses constrangimentos que dão lugar no plano quotidiano a técnicas do corpo, para falar como Mauss (2003), classificações, prescrições, construções e confrontações inesgotáveis. É importante pensar que o corpo é algo produzido na e pela cultura, desnaturalizando e entendendo que o corpo é histórico e, assim, é possível compreender como a noção de corpo é construída. O corpo é mais que um conjunto de músculos, pele, ossos, vísceras, reflexos e sensações, ele é também os adereços de que nos utilizamos, a roupa e os acessórios que o adornam, as intervenções que sofremos. Por isso, é importante desconstruir a visão fragmentada que separa corpo e mente e vivenciar os diferentes meios de se transmitir informações para outras pessoas através do corpo.

A dança, o teatro e as demais manifestações artísticas que evidenciam o corpo são, na maioria das vezes, quem contam histórias de vida das pessoas, falam da tradição; e as manifestações plásticas africanas e indígenas são conhecidas através da produção de máscaras, pintura corporal, desenhos, escultura, tecidos pintados e coloridos que expressam vários significados para a cultura que a produz. Os negros africanos e afrodescendentes "sempre trabalharam e desenvolveram táticas de sobrevivência que possibilitaram a permanência de práticas ancestrais herdadas, reelaboradas por meio de suas experiências cotidianas" (SANTOS, 2018, p. 147). Os indígenas buscaram aplicar táticas que permitissem se defender e resistir. Essas táticas podem ser pensadas a partir do que propõe Certeau (1996, p. 47),

As táticas manifestam igualmente a que ponto a inteligência é indissociável dos combates e dos prazeres cotidianos que articula, ao passo que as estratégias escodem sob cálculos objetivos a sua relação com o poder que os sustenta, guardado pelo lugar próprio ou pela instituição.

Porém, na percepção de Santos (2018, p. 147), "ao contrário do que sugere a noção de estratégia, circunscrita a um lugar próprio e capaz de servir de base a uma racionalidade específica, as táticas atuam pelas brechas do sistema, jogando com os acontecimentos para os transformar em ocasiões". Não é tarefa fácil jogar com os acontecimentos diante de um sistema perverso, preconceituoso e racista, como a sociedade brasileira e suas formas de discriminação e exclusão social. Sendo assim, corpos negros e escravizados "(re)territorializaram-se diante à trituradora máquina da opressão e do racismo, adubando a terra com suas experiências, saberes, espiritualidades, cosmovisões e formas de luta" (p. 143). Nesse processo contínuo, "a partir 
das cosmovisões que se encontram no contexto da diáspora e atuam de forma a desconstruir e descolonizar a ordem dominante por meio de cruzamentos interculturais" (p. 148), é possível perceber a múltipla pertença à espiritualidade. Por exemplo, onde a matriz ioruba se manifesta num contexto em que os elementos da natureza se apresentam, a partir do culto aos orixás, na tentativa de potencializar força vital (axé) dos seres e, por outro lado, caboclos e conhecimentos sobre a floresta evocam permanências das diferentes matrizes indígenas.

O cristianismo popular também atua nesta lógica, já que as rezas e os santos são recorridos para o trabalho com o sagrado (SANTOS, 2018, p. 148) e, nessa perspectiva, operam a arte, o corpo e a memória, mediados por experiências cosmológicas, apresentando como lógica o lugar da cultura afrodescendente, afro-indígena, afrodiaspórica reterritorializada e irradiada nos espaços de vida, luta e resistência. Nesse processo, fazem interligações entre natureza, cultura, vida e

Os vínculos entre cultura e natureza de comunidades africanas e da diáspora são históricos, dispõemse desde condições físicas de vida e imaginários que norteiam e informam suas visões de mundo, sem esquecer que seus corpos e de outros seres se inserem nessa mundivivência, são feitos e disponibilizados em suas perspectivas de interações entre o mundo humano, natural e sobrenatural. (ANTONACCI, 2014, p. 249).

Corpos, histórias e lembranças do passado emergem a partir das memórias negras, indígenas e afro-indígenas, sendo que o corpo se tornou um instrumento de luta e resistência e uma entidade na qual estão escritas as manifestações culturais. O corpo passou por significações e subjetividades, mas nunca deixou de ser ele próprio. No entanto, sempre reconhecido como emissor de mensagens, diálogos e, assim, se apresenta com objetivo de estabelecer algum tipo de comunicação, de interações. Para Bordo (1997, p. 20), o corpo, "o que comemos, como nos vestimos, os rituais diários através dos quais cuidamos dele - é um agente de cultura" e, nesse sentido, pode funcionar como "uma metáfora de cultura" e "não é apenas um texto da cultura", é o que nos torna presentes no mundo, nas relações sociais e étnicas. Assim, Bordo (1997) cita Douglas (1982) para dizer que o corpo "é uma poderosa forma simbólica", uma superfície na qual as normas centrais, as hierarquias e até os comprometimentos metafísicos de uma cultura são inscritos e reforçados através da linguagem corporal concreta" (p. 20).

O corpo é "um lugar prático direto de controle social", um controle sobre os corpos e o processo social da vida, como define Bourdieu (1975). Enfim, o corpo no contexto afro-indígena é um texto da cultura afro-indígena e é por meio de imagens que nos dizem que roupas, que configuração corporal, que expressão facial, que movimentos e que comportamentos são exigidos, podendo ser assim um instrumento de mudanças, reivindicações, luta e resistência.

O corpo passa por significações e suas formas de representação são diversas. Ele possui muitas concepções, há muitas referências para se apresentar o corpo, o vestuário, as expressões, é capaz de movimentar-se por diferentes espaços e ultrapassar fronteiras e tudo isso pode contribuir para aumentar "o poder do corpo de afetar e ser afetado" (VILLAÇA, 2002, p. 93).

Para Castilho e Martins (2005, p. 93), 
O sujeito, por intermédio do corpo como suporte e meio de expressão, revela uma necessidade latente em querer significar, de reconstruir-se por meio de artifícios inéditos, geradores de significações novas e desencadeadoras de estados de conjunção ou de disjunção com os valores pertencentes à cultura.

Desse modo, é possível pensar o corpo de diferentes formas e, na sociedade contemporânea, surge de formas múltiplas, fundado numa cultura baseada na relação do parecer e não do ser e de valores humanos, mas na produção do consumo e da mercadoria, sem lugar de delimitação e referência. Ele sofre mutações constantes de identidade, passando o corpo a ser objeto de articulador de significantes e de representações de sua cultura. Nesse contexto, a relação das pessoas com as outras, de cada indivíduo com o outro, se dá através da relação com o corpo, de acordo com lugares, vestimentas, modos de vida.

\section{O recorte etnográfico: o lugar da arte e do corpo na escola}

A etnografia buscou entender relações interétnicas entre um grupo de pessoas que se autodeclara afro-indígena, em Caravelas, BA, no período 2018-2019, por meio de depoimentos e práticas sociais e educativas, com foco no lugar da arte, corpo e memória individual e coletiva e tomou como ponto de observação suas formas de organização social, seus modos de fazer e pensar a arte e a construção memorial de diferentes heranças deixadas por suas ancestralidades e redes de sociabilidades.

Para isso, foi preciso ir a campo munida de teorias, traçando o caminho de volta, retroalimentando e transformando-as e, assim, "agitar, fazer pulsar teorias reconhecidas por meio de dados novos, essa é a tradição (PEIRANO, 1995, p. 4). E para fazer etnografia, foi preciso vocação, descentramento como novo olhar sobre o mundo e a realidade concreta, desenraizamento, e buscar tempo prolongado para dialogar com as pessoas, os nativos. Este foi um grande desafio, apesar da experiência do diálogo em pesquisas, mas, agora, ao que parece, o diálogo foi "para valer", como diria Viveiros de Castro (2002).

Em campo, foi possível observar que o Movimento Cultural Arte Manha tem procurado desenvolver ações educativas e artístico-culturais com jovens, adolescentes e crianças nos seus espaços diversos; e o funcionamento dos núcleos de atividades depende das "necessidades" do grupo, que seus responsáveis denominam de ações interdisciplinares, como entalhe em madeira, desenhos, danças africanas e de cultura indígena, rodas de conversas para discutir e refletir sobre temas voltados para a cultura e modos de vida africana, afrodescendentes e indígenas, buscando reconhecer a importância dessas etnias na formação da população caravelense e brasileira pelas suas lutas e resistências e, também, valorizar o conjunto de saberes que contribuíram para a manutenção da tradição, das diferentes linguagens em consonância com a vida cotidiana da sociedade brasileira, enfrentando e combatendo estereótipos, preconceitos, discriminação, racismos e exclusão social, os quais ainda perduram. 
O corpo é uma memória (CLASTRES, 1990, p. 128). Com movimentos do corpo, o Arte Manha procura compartilhar, socializar e divulgar saberes afro-indígenas com estudantes, disseminar a cultura de seus antepassados, buscar espaços de formação da cidadania, combate e enfrentamento aos preconceitos, à discriminação e à exclusão social nos espaços cotidianos das escolas. Essas atividades contaram com a participação de professores de universidades baianas e indígenas da aldeia Pataxó, que dançaram, cantaram e foram monitores da oficina de pintura corporal, além de exposição de instrumentos indígenas e outros objetos de arte.

Além das oficinas, palestras e sessão de filme, foram trabalhados com a participação atenta dos estudantes dessa escola que se envolvem em todas as ações realizadas. O auditório lotado, pessoas atentas e curiosas ficam em silêncio para ouvir, dançam e cantam quando provocadas a realizar essas atividades, dançam o Toré com os indígenas pataxós. Os alunos e observadores participam da oficina de pintura e ficam felizes com pinturas no corpo e atentos para saber cada significado do desenho indígena, conversam entre eles e perguntam sobre as dúvidas que surgem ao longo das oficinas. A troca de saberes entre eles, os indígenas e os monitores dessas oficinas chamou a atenção de todos presentes, pois os participantes curiosos perguntam sobre o assunto e sensibilizam os professores pesquisadores indígenas das universidades que se encontravam presentes em diferentes atividades do movimento e ali, a comunidade escolar tem a oportunidade de conversar com ouvintes, palestrantes presentes.

$\mathrm{Na}$ escola, as ações dependem das "necessidades" do grupo, chamadas de interdisciplinares pelos seus integrantes e coordenadores, como, por exemplo, o entalhe em madeira, os desenhos observados, principalmente a oficina denominada "passarinhar" (realizada com crianças de periferia da cidade e, também, de outras instituições de ensino), danças africanas indígenas, roda de conversa para discutir modos de vida afro-indígena. E a escola é espaço privilegiado para a realização de ações artístico-culturais. O espaço de trocas de saberes e conhecimentos se estabelece entre os participantes de modo transversal. Logo, foi possível observar que o grupo desenvolve atividades com crianças em seus diferentes espaços artístico-culturais, com oficinas e ações no espaço pedagógico do Arte Manha, orientando crianças, adolescentes e jovens da cidade de Caravelas e, também, tem parcerias e intercâmbios com uma escola particular de São Paulo há 15 anos consecutivos, informa Dó, artista plástico, que iniciou participando do grupo como capoeira do Grupo "Penuá", e que se dedicou às artes plásticas e hoje é responsável pelo Ateliê Astúcia, que oferece de oficinas de artes. Ele cuida da confecção de objetos de arte, da organização do sítio, onde está sediado o escritório e espaço de realização de eventos, encontros e roda de conversa do grupo, é diretor da oficina de entalhe de madeira e outros objetos de arte. Este espaço, o Ateliê Astúcia, é um dos núcleos de arte do movimento e todos os anos são realizadas exposições de objetos e coisas, com muitas novidades, com a participação de estudantes de diferentes idades. Diz Dó:

[...] E quando os visitantes e parceiros de diferentes lugares do país chegam, espantam-se com o desenvolvimento das crianças que conheceram no movimento em ano anterior e, todos participam de diferentes oficinas, trocam experiências, trazendo para o Umbandaum também seus conhecimentos, instrumentos musicais, culinária. 
Nas oficinas, o movimento trabalha com produção de filmes, teatro, músicas, dança, poesia, desenhos afro-indígenas, pintura corporal, com a parceria de comunidades indígenas de diferentes aldeias da região e de outras cidades baianas e do país. Itamar informa que "Dó segue a sua vontade, acreditando no grupo, desde sua fundação". É interessante destacar ainda que, nas palavras de Dó, a arte é vida, está sempre vinculada à sua estrutura estética e revela uma realidade. $\mathrm{O}$ artista vive da arte, criou seus três filhos com a arte e utiliza a arte como modo de sobrevivência, mas, sobretudo, como aspecto de luta, resistência e transformação. Dó é um homem calmo, simples, cuida do sítio, ara, planta, cuida dos animais, aprecia os pássaros e educa as crianças para também cuidar, admirar, observar e produzir "pinturas observadas"; mora no sítio, onde fica a sede do movimento, preserva, planta e colhe frutos, raízes e folhas e segue assim, utilizando o etnoconhecimento de seus parentes, amigos e vizinhos e gosta da arte que aprendeu a saber-fazer-fazendo com seus avós, pais, irmãos mais velhos e outras pessoas do seu círculo de convivência, vida e experiências na roça. Durante a entrevista gravada, Dó diz:

Eu costumo sempre falar que, pelo assim, eu acompanhei já, um pouco já no finalzinho da adolescência, todo esse trabalho, porque eu ficava na roça. Eu acompanhava tudo isso, mas com outros olhos, eu fazia parte de um grupo de capoeira, já em 85, chamava "Capoeira Penuá". Era uma capoeira de Angola de rua, sem mestre, e eu até então não fazia teatro.

A dimensão de sociabilidade pelo grupo chama atenção e, na posição de pesquisadora, foi possível entender que esse espaço gera novas formas de relações sociais, parcerias e alianças para realizar ações. O movimento utiliza estrutura própria e experiências de alteridade, vividas no interior do grupo e de maneira bastante intensa, através de relações de sociabilidade e educação em direitos humanos (EDH). Essas relações se intensificam em ambientes de sociabilidade virtual, conectados com localidades dentro e fora de Caravelas. A participação em ações pedagógicas na escola foi muito importante para entender de que forma o grupo faz para compartilhar, socializar e divulgar saberes afro-indígenas, disseminar cultura de seus antepassados, buscar espaços de formação e cidadania na escola. Para Itamar,

É, tem uma pegada legal! A gente gostaria de fazer mais. Isso aqui era para ser uma escola. Olhe, já pensou uma sala de aula embaixo dessa gameleira aqui? Nesse lago, para se estudar biologia, até peixe está pulando, aí até jacaré tem aqui. Imagina, uma escola.

$\mathrm{Na}$ fala de Itamar, foi possível perceber que nasce uma outra ação criativa que aguarda apenas a oportunidade de construir um espaço de aprendizagens, em que as pessoas poderão aprender ali, abaixo da gameleira, estudar, como insinua ele, os peixes, jacarés, dentre outros animais e saberes sobre a natureza, o meio ambiente, que o espaço oferece. Apesar de que, de forma ainda tímida pela falta de recursos financeiros para ampliar essas atividades com crianças, o movimento já realiza algumas oficinas de pintura corporal e em tela, desenhos observados, artes plásticas, produção de artesanatos afro-indígenas, com apoio de monitores dos diferentes núcleos do movimento.

De forma tímida, pela falta de recursos financeiros para ampliar ações, o grupo realiza oficinas de pintura, desenhos observados, artes plásticas, com crianças de 7 a 12 anos de idade 
e anda preocupado com a divulgação e a socialização de informação para aumentar o número de participantes, dando a entender que é preciso ampliar o acesso de crianças para ampliar também a quantidade de colaboradores e monitores e não permitir que o movimento tenha dificuldade de caminhar à frente. Na entrevista gravada, foi perguntado a Dó se as oficinas do movimento atendem também crianças da cidade com oficinas pedagógicas e se ele poderia falar um pouco sobre esse trabalho, como desenvolve e quais são as oficinas que contam com a participação de crianças. Ele respondeu que sim, mas relata quais as dificuldades que o grupo tem enfrentado para a realização dessas atividades, como a falta de monitores, que perderam porque alguns deles mudaram de religião, sendo agora evangélicos, outro porque está fazendo tratamento de saúde em outro estado brasileiro e outros devido a conflitos na família. Ele diz:

Sim. Com certeza, a criança se insere tanto na capoeira quanto na dança. Esse ano a gente não teve monitor de dança disponível, como voluntário. E a gente não conseguiu fazer nem na música, o nosso professor de música teve que fazer uma sonografia em Santa Catarina, uma das professoras de dança virou evangélica, as duas. Então, eu não quero muito entrar nesse mérito, mas assim, tem esses fatores também. Conflitos dentro da família 'faz' com que as pessoas se transformem de forma bem radical. $E$ a gente não tem como entender isso de uma forma assim. Isso só a pessoa mesmo pode dizer um dia. A gente espera que um dia volte!

Para Dó, a participação de crianças em oficinas pedagógicas e de arte passa por dificuldades e exige atenção do grupo.

Esse ano precisamos focar um pouco mais na criança. $O$ ano passado a gente perdeu alguns monitores, outros estavam muito ocupados. Lilian, por exemplo, [es]tava trabalhando de assessora pra presidente da Câmara e ficou só eu aqui dando artes plásticas pra criançada e Cleison, percussão pra meninada. As únicas atividades, só as artes plásticas e a música, dança, música de corda. A capoeira é lá [no Dandara], à noite, mas estava com pouca criança. A gente precisa ter um foco esse ano na criança porque cresce rápido. Você pega uma criança de 10,12 anos, com 2 anos, cara, já é adolescente, já tá no grupo de adulto, já.

A ausência do poder público na participação da educação de crianças e produção de artes em Caravelas é percebida pelo movimento, por exemplo, uma grande falta de interesse na socialização e na divulgação da cultura local e história da cidade. As escolas ainda demonstram desinteresse pela valorização e manutenção de atividades dessa natureza, sendo que algumas delas já abrem seus portões para atividades artístico-culturais, mas de forma ainda muito tímida. É preciso aumentar o envolvimento das pessoas no processo. Caravelas é uma cidade histórica e tem o turismo como uma de suas principais atividades, mas "ainda não aprendeu a valorizar o que tem para as pessoas que visitam a cidade e até os nativos mais novos não conhecem muita coisa daqui", diz Dó. Neste caso, foi possível observar que seria importante saber como essas pessoas se percebem de uma maneira ou de outra em relação a este assunto.

A relação pedagógica entre os informantes e as crianças durante as aprendizagens com desenhos é bastante interessante e interativa. Eles compartilham saberes, trocam experiências, passeiam ao ar livre entre árvores, caminham pelas trilhas, observam pássaros com uso de binóculos, provocam discussão sobre pertencimento, sensibilidade, sentidos e são orientados e preparados para aprender a desenhar pássaros e paisagens observados. Dó explica os procedimentos metodológicos, as técnicas e os recursos utilizados por ele nas oficinas de 
desenho observado, desenvolvido com crianças, na faixa etária de 6 a 12 anos de idade, com grupos de 7 a 10 crianças para permitir melhor aprendizagem.

Trabalhamos, ali tem desenhos deles. Eu tinha um grupo de nove deles. Eu trabalho sempre nessa média de 7, 9, até 10, só, senão fica muita gente. Dava aula de observação de pássaros, o desenho observado. Aí uns observam com binóculos e passam observação para os outros, aí pra desenhar pássaros, misturar porque você não pode só trabalhar arte, só por fazer arte. A arte tem que ter um sentido mais de pertencimento, o que que isso aqui faz parte, o pássaro, a arvore, o ambiente, dentro do que a gente está construindo aqui, um espaço onde todo mundo entra, fica ali sentadinho. (DÓ, fev. 2019).

Na conversa com Jaco, foi perguntado a ele qual a sua percepção sobre esse trabalho de arte do desenho observado que o movimento vem realizando com crianças e adolescentes. Ele respondeu que este trabalho com crianças "é educativo e pedagógico e acho interessante porque a pessoa usa a sua imaginação e o processo de criação nasce na percepção e há uma relação entre a arte e o pensamento". E é uma atividade que "entra também a ação criativa para a construção do conhecimento. Ele sai por aí, observa e desenha, também conversa com as outras, busca identificar cores" (JACO, fev. 2019). As atividades "criativas", como eles denominam, exibem observação, atenção, sensibilidades, ações que são realizadas com diálogo e reflexões e estão presentes na escola, na rua, nos espaços onde trabalham com desenhos com alunos de diferentes idades, em outras oficinas desenvolvidas nos espaços do movimento (onde estão à disposição dos visitantes alguns desenhos realizados pelas crianças, filhos de pescadores da cidade e de outros espaços sociais). Essas atividades são muito importantes, pois a construção da identidade do movimento se dá no processo relacional e o corpo é o instrumento utilizado para expressar a construção da identidade e da cidadania.

O movimento de Caravelas falou sobre a preocupação do grupo com a valorização das formas e das cores do corpo operante na dança e na percussão Umbandaum, em que corpo e subjetividade na arte, na política, na educação e na cultura se entrelaçam e produzem espetáculo. Contudo, o que importa para o movimento não são "os espetáculos para as pessoas de fora e de dentro", nem o olhar dos espectadores e nem fazer "espetáculo para turistas ver", mas "mostrar o que a gente sabe fazer-fazendo arte, heranças de nossos antepassados", diz Itamar. Na conversa informal no Dandara, em março de 2018, enquanto aguardava a chegada dos integrantes do grupo para a nossa primeira roda de conversa, o interlocutor comentou que "leva as coisas ali a sério", "não gosta e não aceita fazer oba, oba, pois é coisa séria (...)". Essa colocação despertou a minha curiosidade. Se não é espetáculo, então é o quê? Por que não caracterizar um "espetáculo" como um espetáculo? Não há possibilidade de evitar os olhares dos turistas, eles estão lá, no circuito da festa, no teatro, nos encontros.

Contudo, foi possível entender que o artista, nesse momento, recorda a participação do poder público em comemoração às datas festivas da cidade, principalmente o carnaval, sua principal festa popular, e que se utiliza desses momentos para fazer politicalha, jogo de interesse político partidário. As apresentações artístico-culturais por eles organizadas e socializadas com o público exibem estética, muita luz, boa música e dança, um batuque maravilhoso, que mexe com quem ouve e assiste, ao que parece, é único, "o som dos tambores nem fazem barulho", 
diz Dó. Os dançarinos "devem acompanhar as batidas fortes e as mais fracas dos tambores para fazer seus movimentos e coreografias", orienta Itamar.

Como reconhecer de outro modo, senão como um "espetáculo". Mas um "espetáculo" que exibe uma história, um enredo sobre relações étnico-raciais. A cultura negra e indígena faz reivindicações para combater a discriminação racial e social e busca por espaço. Não é um "espetáculo das raças". O propósito do grupo é promover manifestações para provocar, mexer, atrair pessoas para suas ações impregnadas de reivindicações sobre o direito de exercer cidadania e dizer não às ações de sincretismos, preconceitos, discriminação e racismos. Para o grupo, este é o momento de usar estratégias de sobrevivência, luta e resistência. As práticas culturais afro-indígenas, ao darem origem às relações artístico-culturais de produção do grupo, se constroem no mesmo tempo em que criam espaço de cultura e espetáculos com luz, cor, movimentos, sentidos, boa música, dança e performance e, no contato com outros grupos, elas se fazem presentes no modo de vida afro-indígena.

De acordo com o caminho que percorri, observei que o grupo Umbandaum demarca seu território de pertencimento e existencial individual, coletivo e institucional, de diferentes dimensões da luta antirracista, como formas de provocação e dimensão disruptiva da colonialidade e, ao que parece, uma manifestação que se apresenta como possibilidade de corpos/sujeitos decoloniais de justiça social e racial, vinculada às políticas do corpo e poéticas do corpo e espaço-tempo, como denota Bakhtin (2003).

As discursividades do corpo-arte e a familiaridade com o corpo-dança afro-indígena, ao que parecem, estão profundamente arraigadas na vida dos afro-indígenas de Caravelas, aumentando a solidariedade do grupo, que organiza suas atividades coletivas e facilita a associação na ação Arte Manha e Umbandaum. A busca de abertura para as fronteiras e resistências entre lugares e modos de subjetivação afrodescendente e indígena se fazem presentes na vida dos afro-indígenas de Caravelas, que levam a sério suas reivindicações, pensamento, origem e lutas contra as contradições da política local e a falta de apoio a negros, índios, pobres, que ainda não tiveram a oportunidade de escolarização.

Nessa perspectiva, a construção de um corpo afro-indígena, isto é, de corpos negros, indígenas e afro-indígenas em zonas de contato interculturais se apresentam na construção subjetiva, a partir de vestimentas, gestos, olhares, memórias de personagens negros e indígenas; e expressam identidades étnicas e sociais nesse encontro, permeado de tensões e conflitos histórico-culturais na história da sociedade brasileira. Na fala de Itamar dos Anjos, o carnaval Umbandaum "não se baseou na tropicalidade, apesar de grande admiração por Gilberto Gil, Caetano Veloso, dentre outros e nem no modernismo, mas na cultura e modos de viver e criar de Abdias do Nascimento".

Ao optar pela carnavalização da linguagem, dos ritmos, o artista Umbandaum elege a figura do outro como forma de homenagear, agradecer e produzir sujeitos, assim, o pertencimento ao movimento vai sendo construído por meio das vivências afro-indígenas, através da cadência dos tambores, com um batuque próprio, do ritmo da dança, de rituais 
políticos, religiosos e artístico-culturais e relações de parentesco - todos ali são considerados parentes, sem distinção. Para o movimento, o territorial existencial é um lugar de pertencimento do eu e do nós, um espaço onde se encontra de modo bem particular e, também, coletivo, a herança, a história, o corpo-arte e a arte-corpo, a relação com seus ancestrais, um espaço no qual a arte "torna-se um suporte de uma produção de afetos e de perceptos que tenderá cada vez mais a se excentrar em relação aos quadros e coordenadas pré-formadas" (GUATTARI, 1992, p. 129).

No entendimento de Silva (2010), a dança é o "uso extracotidiano no movimento cultural" e "não exclui nenhuma das inúmeras formas de dançar que existem, artísticas ou não" (p. 3). O bloco Umbandaum exibe nas ruas da cidade de Caravelas a dança como arte do corpo, do corpo nu, esculpido, franzino, pintado, com uso consciente do movimento, de rituais de matrizes africanas e cultura indígena brasileira. O professor de artes de Itamar não lhe permitiu a participação na sala de aula/escola, mas o seu desejo de saber-fazer arte, teatralizar com seus colegas nas aulas de educação artística, que já se manifestava desse quando ele era criança e ele soube muito bem aproveitar a oportunidade no movimento que ele próprio criou com seus amigos.

\section{Considerações Finais}

A etnografia contribuiu com a construção de um sentimento de pertencimento ao grupo nunca antes vivido numa pesquisa e isto foi possível perceber no momento em que perdi dois ensaios do grupo para o carnaval, outra atividade permanente do movimento, e ficou uma lacuna, um vazio, durante esse período, pois a sensação de que havia perdido momentos de trocas de conhecimentos e saberes afro-indígenas, sensação de alegria, felicidade transmitida pela participação no movimento e oportunidade de vivenciar os modos de experimentar, devir, contagiar através das potências do corpo Umbandaum, em ressonância com processos de singularização e demonstração de sensibilidades e modos de viver a arte, a dança, os movimentos, os batuques, as expressões corporais afro-indígenas.

E a subjetividade no movimento é, tomando como base a análise Guattari (1992), produzida por instâncias individuais, coletivas e institucionais. E as zonas de contato entre o movimento e seus parceiros, colaboradores, integrantes, se dão por agenciamentos de subjetivação; e seus territórios existenciais são construídos a partir de ritmos, dança, músicas, percussão, máscaras, marcas do corpo, através de referenciais ancestrais que circunscrevem outros tipos de "territórios existenciais coletivos".

O corpo Umbandaum, com seu poder de criar, viver, experimentar, afetar, e de ser afetado, com seus modos próprios de viver a dança, os movimentos, a música, as batidas dos tambores, os encontros esperados e inesperados, a ancestralidade, a circularidade, valoriza a roda de conversa como uma das metodologias mais aplicadas pelo grupo, buscando sempre a discursividade, o diálogo, a coletividade e as ações compartilhadas num processo de ensinar 
e aprender a fazer-fazendo, envolvendo modos de sentir, pensar, agir singulares, e essa opção torna seus encontros envolventes e colhedores

A performance do grupo Umbandaum na rua e a arte em relação com o corpo dos dançarinos (nas) os aproximam do teatro, da arte e da memória, fazendo confluências entre esses aspectos e dimensões, a partir do próprio corpo, mas não é um teatro, a performance acontece no tempo real. Para Féral (2015), a performance trabalha "em um duplo nível, procurando, de um lado, reproduzi-lo em função da subjetividade do performer; e, de outro, desconstruí-lo, seja por meio do corpo performance teatral - seja da imagem - imagem do real" (p. 137). E a performance, apesar de ser a obra de arte, produz acontecimento e não objeto, portanto uma relação entre corpo e espaço-tempo.

Pech (2017) aponta que, apesar da divisão que Féral (2015) cita ao falar em performance, "o lugar entre uma e outra divisão existe e se articula de diversas formas. Isto porque a produção de performance sempre buscou quebrar seus próprios parâmetros, algo que o faz ainda hoje, cada vez mais" (p. 10). É assim que os afro-indígenas de Caravelas conduzem as teias da memória e a construção de um passado que, por sua vez, é também fruto de criação e de novas experiências subjetivas e afro-indígenas em Caravelas - BA, focando o corpo como centro das políticas, no sentido de (des)racializar e pluralizar os espaços sociais, a arte, os objetos e as coisas e traçam esse percurso em busca da memória. Devido à falta de recursos financeiros para a confecção de suas fantasias, ornamentos, atividades artísticas e culturais, utilizam como matéria-prima o barro, troncos de árvores mortas, flores e folhas de plantas, dentre outros recursos da natureza para se vestir, organizar e enfeitar espaços de festas e atividades artístico-culturais realizadas pelo grupo nas zonas de contato, com seus parceiros, colaboradores, integrantes, para, como se pode observar, fazer vestimentas e adereços dos dançarinos, confeccionados de folhas de palmeiras. O corpo negro é explorado criativamente e as tradições de matrizes africanas são apresentadas com estética e, nesse sentido, no campo das artes, é o corpo negro em cena que fala de si e do outro.

O grupo é um quasar. É possível perceber que as experiências vividas pelos afroindígenas de Caravelas envolvem não somente a corporalidade imediata, mas um conjunto de valores, sentimentos, atitudes, memória, corporalidade, teatralidade, sentidos e significados mobilizados pelos agentes sociais e sociedade caravelense e outros espectadores que assistem às suas apresentações e aos movimentos artísticos e político-culturais. No entanto, tem no corpo seus componentes afro-brasileiros e indígenas singulares e utiliza o corpo-arte, a artecorpo como um desafio à construção do mundo afro-indígena, desenvolve sua concepção de ancestralidade para muito além das relações consanguíneas ou de parentesco simbólico (OLIVEIRA, 2012), buscando sempre o contato com os parentes de dentro e de fora.

Para os integrantes do Umbandaum, o carnaval é um momento social e político, um momento em que o grupo e seu bloco carnavalesco assumem um sentido afirmativo e valorizado como um meio de promoção da descendência afro-indígena. Dessa forma, estão garantidos a diversão e o entretenimento aos seus membros integrantes e aos de fora 
(pesquisadores, turistas e pessoas da cidade que, nesse período carnavalesco, se colocam em circulação e se incluem no movimento afro-indígena e na expressão no corpo do ator), expressando e socializando noções de pertencimento, cidadania e de antropologia artísticocultural, construídas pelo Arte Manha, especificamente, pelo seu núcleo de dança e percussão Umbandaum, uma expressão de emoção e sentimento, como forma primeira de relação com os seus antepassados negros e indígenas.

Com apoio de Mauss (2003), pode-se observar que a simbólica corporal do Umbandaum apresenta uma representação da realidade e é criadora dessa realidade, um corpo que pensa e se prepara para "pensar em movimento" e com confluências entre arte e educação procura produzir cultura na lógica afro-indígena caravelense. O corpo Umbandaum tornou-se fundamental à performance, os espectadores param para ver o desfile do bloco de carnaval e o grupo de percussão Umbandaum em cima das calçadas, nas portas, janelas, sacadas, varandas. O bloco é uma obra de arte, os movimentos exibem a criatividade do artista, treinado para manter-se com os pés no chão e um corpo que dobra, mexe, inclina para os lados, com muita facilidade, exibindo estética e beleza e, ao seu redor, as(os) dançarinas(os) fazem o mesmo, seguem os ritmos do mestre.

Há uma conexão profunda entre eles, harmonia, graciosidade, gentileza e a qualidade da presença do corpo na rua torna-se indispensável à socialização da cultura de seus antepassados, para se fazer notar negros e indígenas, desfilando no espaço onde antes eram proibidos de pisar, entrar e conviver com as pessoas que moram no circuito e que, hoje, o grupo permite viver o espetáculo e uma expressão de luta e resistência. As ruas e as praças principais da cidade ficam sem espaço vazio, todos os lugares são ocupados com grupos de observadores, foliões, turistas, que tomam as ruas para ver o bloco passar, desfilar e se mostram eufóricos, tiram fotos, filmam, acompanham, dançam, cantam juntos. A conexão entre o bloco e as pessoas ao seu redor é visível, são encontros confluentes que permitem ao grupo ser um corpo de transmissão de cultura africana e indígena. Nesse processo, a multidão e o bloco se tornam um corpo de transmissão e de energia da presença afro-indígena nas ruas de Caravelas.

Desse modo, podemos considerar que o movimento Arte Manha é um movimento social, cultural, militante, com oito núcleos de atividades artístico-culturais em pleno desenvolvimento, valorizando o corpo-arte, a arte-corpo e suas confluências com a arte-educação. E, especificamente, o seu núcleo Umbandaum é uma arte em movimento, como manifestação política, educativa e artístico-cultural, que procura, através da criatividade e de uma "necessidade", dizer à sociedade e à escola o que pensa sobre a política local e nacional, combater estereótipos, estigmas, preconceitos e discriminação de raça, etnia, gênero, classe social, dentre outras questões que atingem negros, índios, pessoas de baixa renda, moradores da periferia, atuando em zonas de contato, na cidade de Caravelas e em outros espaços baianos e do país. 


\section{Referências}

ALENCASTRO, Luiz Felipe de. Geopolítica da mestiçagem. In: Novos Estudos, n. 11. Jan de 1985, p. 49-63. Tradução Maria Lúcia Montes. Disponível em: http://novosestudos.uol.com.br/ produto/edicao-11. Acesso em: 20 de mar. de 2018.

ANJOS, José Carlos Gomes dos. No território da linha cruzada: a cosmopolítica afro-brasileira. Porto Alegre: Editora da UFRGS/Fundação Cultural Palmares, 2006.

ANJOS, José Carlos Gomes dos; ORO, Ari Pedro. Festa de Nossa Senhora dos Navegantes em Porto Alegre: sincretismo entre Maria e lemanjá. Porto Alegre: Secretaria Municipal de Cultura - SMC, 2009.

ANTONACCI, Maria Antonieta. Memórias ancoradas em corpos negros. São Paulo: EDUC, 2014.

BAKHTIN, Mikhail M. Estética da criação verbal. São Paulo: Martins Fontes, 2003

BARTOLO, José. Corpo e sentido. Estudos Intersemióticos. Covilhã: Livros LabCom, 2007. (Série: Estudos em Comunicação)

BHABHA, Homi K. O local da cultura. Tradução Myriam Ávila, Eliana Lourenço de Lima Reis, Gláucia Renate Gonçalves. Belo Horizonte: Editora UFMG, 2013.

BLOCH, Marc. A sociedade feudal. Lisboa: Edições 70. São Paulo: Martins Fontes, 1982.

BORDO, Susan R. O corpo e a reprodução da feminidade: uma apropriação feminista de Foucault. In: JAGGAR, Alison M.; BORDO, Susan R. (Orgs.). Gênero, corpo, conhecimento. Tradução Britta Lemos de Freita. Rio de Janeiro: Record: Rosa dos Ventos, 1997.

BOURDIEU, Pierre. A economia das trocas simbólicas. São Paulo: Perspectiva, 1975.

BOSI, Ecléa. Memória e sociedade: lembranças de velhos. São Paulo: T.A. Queiroz, 1979. Companhia das Letras, 1994.

CANDAU, Jöel. Identidade e Memória. Tradução Maria Letícia Ferreira. São Paulo: Contexto, 2005.

CERTEAU, Michel de A. A invenção do cotidiano. 2:Morar, cozinhar. Petrópolis, RJ: Vozes, 1996.

CLASTRES, Pierre. A fala sagrada: mitos e cantos sagrados dos índios Guarani. Tradução Nícia A. Bonatti. Campinas, SP: Papirus, 1990.

COSTA, Sérgio. A mestiçagem e seus contrários - etnicidade e nacionalidade no Brasil contemporâneo. In: Tempo Social. Revista de Sociologia da USP, v. 13, n.1, p. 143-158, maio de 2001. São Paulo: USP, 2001. Disponível: http://www.revistas.usp.br/ts/article/view/12354 Acesso: 2 dez. 2017. DOI: https://doi.org/10.1590/S0103-20702001000100010.

FÉRAL, Josette. Além dos limites: teoria e prática do teatro. São Paulo: Perspectiva, 2015.

GUATTARI, Félix. Caosmose: um novo paradigma estético. São Paulo: Editora 34, 1992. 
DOCUMENTA. "Quinhentos anos decontato":por uma teoria etnográfica da (contra)mestiçagem.

Revista Mana. Estudos de Antropologia Social, v. 21, n. 3, Dec. 2015a. p. 641-659. Disponível: http://www.scielo.br/scielo.php?script=sci_arttext\&pid=S0104-93132015000300641. Acesso: 12 dez. 2017. https://doi.org/10.1590/0104-93132015v21n3p641

GOLDMAN, Márcio. A relação afroindígena. Cadernos de Campo, São Paulo, n. 23, p. 213-222, 2014. Disponível: http://www.revistas.usp.br/cadernosdecampo/article/ view/98442 Acesso: 22 dez. 2017. DOI: https://doi.org/10.11606/issn.2316-9133.v23i23p213-222

LUCIANI, José Antonio Kelly. Sobre a antimestiçagem. Tradução Nicole Soares, Levindo Pereira e Marcos de Almeida Matos. Curitiba, PR: Species - Núcleo de Antropologia Especulativa: Desterro, Florianópolis: Cultura e Barbárie, 2016

MAFFESOLI, Michel. As máscaras do corpo. Libero, Ano III, v. 3, n.6, 2000.

O tempo das tribos: o declínio do individualismo nas sociedades de massa. Rio de Janeiro: Forense-Universitária, 1987

MAUSS, Marcel. Sociologia e Antropologia. São Paulo: Cosac Naify, 2003.

MELLO, Cecília C. do A. Devir-afroindígena: 'então vamos fazer o que a gente é'". Cadernos de Campo,v.23, n.23, 2014, p. 223-239. Disponível: http://www.revistas.usp.br/cadernosdecampo/ article/view/98443 Acesso: 20.abr.2017. DOI: https://doi.org/10.11606/issn.2316-9133. v23i23p223-239

Obras de arte e conceitos: cultura e antropologia do ponto de vista de um grupo afro-indígena do sul da Bahia. Dissertação de Mestrado. Programa de Pós-Graduação em Antropologia Social (PPGAS). Museu Nacional, UFRJ, 2003.

OLIVEIRA, Eduardo D. de. Filosofia da ancestralidade como Filosofia Africana: educação e cultura afro-brasileira. In Revista Sul-Americana de Filosofia e Educação - RESAFE, n. 18, maio-out. 2012, p. 28-47. DOI: https://doi.org/10.26512/resafe.v0i18.4456

PACHECO, Agenor S. Afroindigenismo por escrito na Amazônia. In RELACult - Revista LatinoAmericana de Estudos em Cultura e Sociedade. v. 3, ed. Especial, dez., 2017, artigo n. 645. Disponível: http://periodicos.claec.org/index.php/relacult/ article/view/645 Acesso em: 12.fev.2018. DOI: http://dx.doi.org/10.23899/relacult.v3i3.645

Astúcias da memória: identidades afroindígenas no corredor da Amazônia. Revista Tucunduba, n. 2, 2011. Disponível: http://www.revistaeletronica.ufpa.br/index.php/tucunduba/ article/viewArticle/46 http://revistaeletronica.ufpa.br/index.php/tucunduba Acesso: 20.fev. 2017.

PECH, Andrea. Performance, teatralidade e contemporaneidade. In: Revista Landa, v. 6, n.1, 2017, p. 7-21.

PEIRANO, Mariza. A favor da etnografia. Rio de Janeiro: Relume-Dumará, 1995.

PRATT, Mary Louise. Os olhos do império. Relatos de viagem e transculturação. Bauru: EDUSC, 1999.

SANT'ANNA, Denise Bernuzzi de. Corpos de passagem: ensaios sobre a subjetividade contemporânea. São Paulo: Estação da Liberdade, 2001. 
SANTOS, Bruno Garcia dos. Cosmovisões afrodiaspóricas na América Latina: protagonismos femininos marcados por práticas ancestrais na zona norte de São Paulo, Brasil. In: Ciencias Sociales y Religión, Porto Alegre, ano 20, n. 28, p. 142-157, jan.-jul. 2018. DOl: https://doi. org/10.22456/1982-2650.85017.

SILVA, Renata de Lima. O corpo limiar e as encruzilhadas: a Capoeira Angola e os Sambas de Umbigada no processo de criação em Dança Brasileira Contemporânea. (Tese de Doutorado). Programa de Pós-Graduação em Artes do Instituto de Artes da UNICAMP. Campinas, SP: 2010.

VELLOSO, Monica Pimenta; ROUCHOU, Joëlle; OLIVEIRA, Cláudia de. Apresentação. Corpo: uma obra inconclusa. In: Janeiro: Mauad X, 2009. p. 15-17. (Orgs.). Corpo: identidades, memórias e subjetividades. Rio de VIGARELLO, Georges. O corpo inscrito na história: imagens de um "arquivo vivo". In: Projeto História, n. 21, novembro de 2000.

VILLAÇA, Nízia. Alta, média e baixa costura: modo e semiologia cultural. In: CASTILHO, Kathia; GALVÃO, Diana (Org.). A moda do corpo e o corpo da moda. São Paulo: Esfera, 2002, p. 91104.

VIVEIROS DE CASTRO, Eduardo. O nativo relativo". Mana. Estudos de Antropologia Social, v. 8, n.1, 2002. p. 113-148. https://doi.org/10.1590/S0104-93132002000100005 